\title{
Environment change, economy change and reducing conflict at source
}

\author{
A. Cottey ${ }^{1}$ \\ Received: 20 April 2017 / Accepted: 22 January 2018 / Published online: 6 February 2018 \\ (c) The Author(s) 2018. This article is an open access publication
}

\begin{abstract}
At a time when fossil fuel burning, nationalism, ethnic and religious intolerance, and other retrograde steps are being promoted, the prospects for world peace and environmental systems stability may appear dim. Exactly because of this is it the more important to continue to examine the sources of conflict. A major obstacle to general progress is the currently dominant economic practice and theory, which is here called the economy-as-usual, or economics-as-usual, as appropriate. A special obstacle to constructive change is the language in which economic matters are usually discussed. This language is narrow, conservative, technical and often obscure. The rapid changes in the environment (physical and living) are largely kept in a separate compartment. If, however, the partition is removed, economics-as-usual, with its dependence on growth and its widening inequality, is seen to be unsustainable. Radical economic change, for better or worse, is to be expected. Such change is here called economy change. The change could be for the better if it involved an expansion of the concept of economics itself, along the lines of oikonomia, a modern revival of a classical Greek term for management or household. In such an expanded view, not everything of economic value can be measured. It is argued that economics-as-usual is the source of much strife. Some features are indicated of a less conflictual economy-more just, cooperative and peaceful. These features include a dignified life available to all people as of right, the word 'wealth' being reconnected with weal, well and well-being, and 'work' being understood as including all useful activity.
\end{abstract}

Keywords Economic change $\cdot$ Economy change $\cdot$ Economy-as-usual $\cdot$ Oikonomia $\cdot$ Stability $\cdot$ Conflict $\cdot$ Peace

\section{Introduction}

When, in the context of 'world peace and environmental systems stability', the terms 'global', 'globalisation', and 'local' are used, it is clear that they refer to spatial extent and the spatial scales, in context, are reasonably clear. There is, of course, another relevant dimension, namely time, and the inclusion of 'stability' indicates this. 'Peace' also generally suggests a degree of stability. It has often enough been remarked that a world in which perfect peace reigned worldwide and in which global environmental systems were highly stable would be boring. Even Kant (1795), a philosopher not noted for a humorous approach, opens his essay Perpetual Peace (p 3) by making a comparison with a graveyard. In the present times, however, it is important to examine and

$\triangle$ A. Cottey

a.cottey@uea.ac.uk

1 School of Chemistry, University of East Anglia, NR4 7TJ Norwich, UK continually re-examine the sources of human conflict and destructiveness.

In this complex web of concern, one problem has received insufficient notice and is a sticking point that impedes general progress. This obstacle is public economic discourse, that is, the language in which economic matters are defined and publicly presented by economists, bankers, politicians, administrators, business leaders and the mass media. The language shapes a public consensus about what is normal and practical. The present paper challenges that consensus and proposes a distinction between economic change (minor quantitative changes within an economy-as-usual) and economy change (a radical change, of whatever kind, to a completely different economy). In particular, reconnection of the term economy with its Greek root-oikonomia, meaning management or household-is advocated. With such an expanded usage, important contributions which are not counted in the usual economy, such as unpaid work, are included. In view of the rapid changes underway in the physical and living environment, economy change is to be expected, and indeed on a short timescale, possibly very 
short and surely no more than a few decades. And if economy change, of some kind, is to be expected, it makes sense to try to make it positive, rather than, as is all too common at present, to deny it or to deny that humans can choose.

The economic structure of a society, and of societies with which it interacts, is a major factor influencing the manner in which conflicts of interest play out. This paper avoids advocating any blueprint for an economy-as-a-whole or for world peace. It does, however, propose that respect for the physical and living environment, justice, cooperation, and restraint are values that would promote a more peaceful world, in which conflicts of interest were acknowledged realistically and resolved in a proportionate manner. Several features that could contribute to a peaceful oikonomia are described briefly - the necessities for a dignified life available to all people as of right; wealth recapturing its meaning surrounding such words as commonweal, etc; work defined so as to include all useful activity; limits to the accumulation of property.

\section{Systems, change and stability}

In the present context, system is taken in general to mean an organised body of material or immaterial things. The particular systems of interest are cultural systems, ecological systems and those physical systems, such as the global climate, whose impact on cultural and ecological systems is problematic and urgent. In the cultural category, economic systems will be of concern, with special attention to the stark separation between quantitative economic models and the practise of political economy. All of the systems of interest change with time and the range of timescales is very great. The speed and extent of change affects what is considered (there being no objective criterion) to be stable or unstable.

\subsection{Economy-as-usual as a system}

The currently dominant economy, an economic system, is here dubbed economy-as-usual; and the corresponding practise of study and application is economics-as-usual. They have widely recognised characteristics-notably individualism, market orientation, emphasis on supply and demand, weak regulation, rapid growth and increasing inequality. One may consider this system to have reached a kind theoretical completion about two-thirds of a century ago-see for example Feser (2006) on Friedrich Hayek and Butler (1985) on Milton Friedman - and to have achieved practical political hegemony about one-third of a century ago with the assumption of political power in 1979 in the UK by Prime Minister Margaret Thatcher and in 1980 in the USA by President Ronald Reagan. Established terms cognate with economics-as-usual are neoliberal economics, neoclassical economics and capitalism. These terms are used with numerous nuances by many authors, for example, respectively, pp 52-61 of Lanchester (2014); Earle, Moran and Ward-Perkins (2017); Schutz (1999). The present paper will not be concerned with the differences between the numerous schools of thought in economics-see, for example, Barnett 2015, pp 25-85 of Costanza et al. (2015); pp 77-85 of Foldvary (2015); pp $35-116$ of Scott Cato (2011). Instead, it will focus on the near-universal features of the currently dominant system, its unsustainability, and how it may change. The current system is so much taken for granted as to be tacitly assumed by many to define economics and 'the economy'. This system plays a large part in cultural discourse as a whole despite the very concept of 'the economy' being a modern development (pp 14-15 of Earle et al. 2017).

A notable feature of economics-as-usual, considered as a system, is that it falls into two weakly interacting parts. One is the set of mathematical models learned, taught and used by professional economists. The narrow focus on these models by the professionals is subject to intense criticism, especially but not exclusively since economists' failure to forestall or anticipate the 2007-2008 financial crisis. An important group of the critics comprises economics students and recent graduates around the world. They mount informed arguments for broadening economics degree curricula which are focused almost exclusively on mathematical models and neglect the teaching even of classical economics (Earle et al. 2017).

The other part of economics-as-usual comprises the learning, teaching and practise of political economy. Here, 'practise' refers to the choices made by those with a training in this subject who hold highly influential positions in government (including administration), business and the media (Beckett 2017). There is a stark division of labour between this power elite and mathematical economists. The former rarely understand the mathematical models, which are indeed complex, and the latter develop and apply the models in a blinkered way. Consequently, the two parts of economics-as-usual, political economy and mathematical modelling, are only weakly coupled.

It is not suggested here that mathematical models have no valid place in economics. On the contrary, such models have an important place in the totality of economics but the models, their limitations and their results, should be presented as clearly as possible. Petit (1990) is an example of a technical exposition without obfuscation or unnecessary jargon. Further, it should be made more clear what parts of a broader concept of 'the economy' have been left out of quantitative analyses and plans. A large amount of this broader material is discussed clearly in, for example, Boyle and Simms 2009; Costanza 2015; Jackson 2012; Scott Cato 2011. 


\subsection{Change}

All systems of interest to this paper (environmental, ecological, economic, political) change with time and the range of relevant timescales is enormous, from geological time for the slower evolutionary developments, through minutes for launch-on-warning nuclear weapon systems, to tiny fractions of a second for automatic global trading. Sometimes, however, economic change is relatively slow or modest. A recent example is the (perceived) Great Moderation. A notable reference to this was made by Ben Bernanke (2004), Chairman of the US Federal Reserve, who claimed that over the previous 20 years or so there had been a substantial decline in macroeconomic volatility. Evidently, Bernanke did not foresee the 'volatility' of 2007-2008, later given various labels, such as credit crunch, sub-prime mortgage crisis, and financial crisis of 2007-2008. In that case, as with many others historically, a build-up of stress is unrecognised. A period of growth leads to unwarranted enthusiasm and suspension of critical judgement (Terzi 1999) followed by a crash.

Another mode of change, between slow and sudden, is represented in the phrase rapid change, which has become widely used, especially in climate science (for example, Seidov et al. 2001). Gradual change (the meaning of this being understood in some context) can be adapted to relatively easily, whereas rapid change causes excessive disruption. This language reflects the recognition that, in the kind of problems considered here, everything does change, so that stability is not stasis. Nor, in complex living or cultural systems is stability as precisely defined as in various fields of mathematics and engineering. Rather, between stability and instability there is a grey region which is the limit of what is tolerable.

In the early stages of the industrial revolution, change was, in the sense indicated, rapid. There was a brutal disruption of communities whose way of life was undermined by the new technologies-ingenious mechanisms, steam power, the factory system (Fielden 1969). Those early stages were followed by a period of adaptation and reform (Henriques 1971), during which change, while not slow, was more considered than in the earlier period.

In a similar way, the period since about 1970 may be considered to be the early 'wild west' stage of other rapid changes. One may think of information technology (IT), or of neo-liberal economics. It is here suggested that these two are connected. IT provided extended scope for very rapid investment analysis and trading, and that drove the trend of deregulation of banking and of stock markets. Further, the great opportunities opened up for those able to move quickly into the new economic space provide a motive for creating and establishing economic language that makes the new developments appear necessary. That language presents the avoidance of an economic instability (general market failure) as a fundamental task in the management of civilised society. In this way a general conservatism (preservation of economics-as-usual) is normalised. In the remaining sections of this paper, this mind-set will be criticised and the need for a major expansion of economic thinking demonstrated, if the conflict that is currently evident in human society is not to get completely out of hand.

\subsection{Stability}

This subsection is primarily about how stability is viewed in economics-as-usual and how planetary limits to growth are largely ignored in the discourse of economics-as-usual. As indicated earlier, there is in economics no objective criterion for stability. This is demonstrated, for example, by the fact that essentially the same period that Bernanke (2004) and others call the Great Moderation (of market volatility) was referred to by Arner (2007) as a series of financial crises. The Introduction to his book opens "why do financial crises occur and what can be done to prevent such crises and reduce their impact when they do occur? Today, following a series of financial crises around the world over the past 15 years, this question has to some extent been answered".

Arner's timing was even more unfortunate than Bernanke's, the introduction being dated January 2007. (The beginning of the sub-prime mortgage crisis, from which much else followed, is given by Elliott (2011) as August 2007.) Another optimistic pronouncement relating to stability was made by Robert Lucas (2003) at the opening of his Presidential Address to the American Economics Association, who said of macroeconomics "Its central problem of depressionprevention has been solved, for all practical purposes, and has in fact been solved for many decades." It is true that the mistaken initial responses to the Great Depression were not repeated in 2007 or the next few years. Nevertheless, this quotation gives a sense of missing something.

Several decades ago, Hyman Minsky proposed (pp 173-175 of Minsky 1986) that capitalism is inherently prone to financial instability. The FIH (financial instability hypothesis) did not gain much support from orthodox economists until the economic events of 2007 and 2008. Even then, the environmental and ecological limitations did not become salient. There is a chasm between economicsas-usual discourse on stability and the discourse found in environment and ecology oriented studies. One indication of the frustration induced in scholars deeply concerned with the global predicament appears almost at the end (p 210) of 'an environmental history of the Anthropocene since 1945', when the authors (McNeill and Engelke 2014) break from their normal magisterial tone to declare that economists have "jilted reality in favour of a different fantasy, one of evermore-abstract modelling based on universalizing assumptions of individual behaviour and state conduct, casually 
ripped from all historical and cultural, not to mention ecological, context."

\section{Environmental system stability}

In Something New Under the Sun, John McNeill (2000) presents 'an environmental history of the twentieth century' (the book's subtitle) which has stood the test of the 17 years to date and is recognised as a classic work. It is, for example, frequently cited in The State of the World 2015 (The Worldwatch Institute 2015), a report that shows that human impact on the global environment has a systemic character (individual components cannot be understood in isolation) and is at risk of producing severe instability.

Global environmental system stability is a matter of great concern in many interconnected subsystems where dangerously rapid large-scale changes are in progress. These changes include falling water tables (pp 21-33 of Brown 2011); tropical deforestation (Fearnside 2015); soil loss (pp 34-44 of Brown 2011); ocean acidification (Gatusso and Hansson 2011); increase of human population (United Nations Population Fund 2016); global warming (Intergovernmental Panel on Climate Change 2017); biodiversity redistribution (Pecl, Araújo, Bell et al. 2017).

Renner (2015) points out that "Environmental change takes place not in linear, predictable ways that can be studied in isolation from other factors, but rather entails unexpected discontinuities, synergisms, feedback loops, and cascading effects." An alarming but not unrealistic type of cascading effect, not mentioned much by political, administrative and business elites, or even by the media and the public, perhaps because it is very alarming, is the 'perfect storm' of Beddington (2009) whose Abstract declares "It is predicted that by 2030 the world will need to produce 50 per cent more food and energy, together with 30 per cent more available fresh water, whilst mitigating and adapting to climate change. This threatens to create a 'perfect storm' of global events." Arguably, these interlocked problems are becoming to manifest already. One such sign comprises horrific developments on the humanitarian front, as reported by the UN Office for the Coordination of Humanitarian Affairs to the Security Council on Missions to Yemen, South Sudan, Somalia and Kenya (O'Brien 2017).

Moreover, human culture is not rising to the numerous challenges with the necessary clarity. Instead, the response is too often denial and obfuscation of the real source of problems-by, for example, the head of the US Environmental Protection Agency (Mooney et al. 2016). Speaking of carbon dioxide to the US business news channel CNBC on 9 March 2017, he said "I would not agree that it's a primary contributor to the global warming that we see" (Milman 2017).
This kind of denial and obfuscation appears to be a present day vindication of the subtitle of Jared Diamond's (2005) study Collapse: how societies choose to fail or survive. (The first, US, edition has the subtitle how societies choose to fail or succeed.) The book was a major popular bestseller but its title, subtitles and content have provoked intense controversy from specialists in many fields. Notable among the many criticisms is Questioning Collapse: human resilience, ecological vulnerability, and the aftermath of empire (McAnany and Yoffee 2010), a collection of articles by anthropologists, archaeologists and historians. Diamond (2010), in turn, has criticised those authors' claims in a book review. In a multi-faceted controversy, reflecting Diamond's broad sweep of societies in place and time, the points of interest for the present paper concern the cultural, psychological and linguistic differences between two attitudes to (the contested) current global environmental system stability. One of these attitudes focuses on 'human resilience', the other on collapse or at least on catastrophe. This paper is not concerned with the many disputes of anthropological, archaeological and historical fact and interpretation between Diamond's Collapse and the collection Questioning Collapse, important as it is of course to avoid errors, even of detail. Without going so far as to pin the labels environmental determinism or geographical determinism, which are indeed strong terms, it can be said that Collapse emphasises environmental factors as the key to understanding the continuation or demise of large, complex societies. Further, in Collapse, the demise is often complete, or almost so. In the multi-author counterblast Questioning Collapse, historical, cultural, political and economic factors are emphasised. It is also maintained that collapse and almost total disappearance (as expressed so graphically in Shelley's 1817 poem Ozymandias, reprinted on p vii of Collapse) is much less common than Diamond suggests. A variety of cultures does persist, adapt or assimilate, as indicated by 'human resilience' in the subtitle of Questioning Collapse.

Whether or not Diamond's attempt to understand how earlier societies 'choose' to 'fail' or 'succeed/survive' was valid, the importance of global environmental system stability is undeniable - for those aware of current knowledge of the Anthropocene. The suggestion that the global environmental changes merited the naming of a new geological epoch, taking over from the Holocene at the beginning of the Industrial Revolution, was proposed by Crutzen (2002). In this article, he mentions several precursor ideas, going back as far as 1864 (Marsh 2014). A concise overview of the evidence for the Anthropocene proposition may be found in Steffen, Crutzen and McNeill (2007)—at the beginning of their abstract ( $p$ 614), they describe the Anthropocene as "the current epoch in which humans and our societies have become a global geophysical force." 
As if this were not enough, the rate of increase of many measures of human influence has itself increased markedly since the end of World War II. The term The Great Acceleration has been coined for this. Steffen, Crutzen and McNeill devote a section (pp 617-618) to this. See especially their Figure 2 which displays the acceleration of 12 important growth indicators. The argument for The Great Acceleration has been set out in more detail in a book with that title by McNeill and Engelke (2014).

The present paper is not concerned with disputes about whether The Anthropocene is technically acceptable to geologists as a new epoch and, if so, when it should start; nor with details of The Great Acceleration such as should its beginning be 1945 or around 1950. The focus here is on 'undeniable'. On the one hand, the scientific evidence and general consensus is strong for a large, rapid and accelerating climate change (World Meteorological Organization 2017). Yet exactly what seems undeniable to virtually all who have studied the subject is denied by powerful actors, notably US President Trump (Parker and Davenport 2016), his senior appointees (Milman 2017) and a powerful fossil fuel lobby (Dunlap 2013). Many influential economists, also, while few are outright deniers, appear to avoid a meaningful engagement with the current precarious state of global environmental system stability. For a comment on one aspect of this, see Lawlor (2016).

The scale and speed of current environmental changes is made possible by technology but humanity does not have to use the available powers so aggressively or recklessly. There are two major aspects of the unwise use of technology-growth and inequality. Both are economic phenomena and both, if unbridled, lead to conflict. The next section will discuss economy-as-usual versus economy change. The final section will discuss the generation of conflict by economyas-usual and ways in which economy change could contribute to reducing the generation of conflict and to managing such residual conflicts as do arise.

\section{Economy-as-usual versus economy change}

The economic system that has dominated the world for nearly half a century is here called the economy-as-usual or, as appropriate, economics-as-usual. It has been highly successful-on its own terms. Two key tenets are that economic growth is vital and that the essential characteristics of the economy, including growth, can be measured. For many, the economy-as-usual has become more-or-less a worldview (see, for example, the critique of Earle et al. 2017). Economics-as-usual has delivered enormous increases in the 'standard of living' (as measured by its own methods) of very many people-a result which is a significant part of the explanation of its world-wide dominance. Besides real benefits there are, however, important drawbacks to those economic conditions, which are seen clearly through an economic lens with a broader field, oikonomia. Unsatisfying consumption, restlessness, loneliness and mistrust cannot be measured but they are significant indictments of life under the economy-as-usual. Three other three problematic aspects—-growth, technology and inequality—are discussed briefly in the following subsections.

\subsection{Growth}

According to economics-as-usual, growth has been sustained (occasional drops, while alarming at the time, are quickly corrected by methods known to economic science) and beneficial. The publication of The Limits to Growth (Meadows et al. 1972) drew a passionately hostile response from economists, for example from Wilfred Beckerman, who in his professorial inaugural lecture (p 331 of Beckerman 1972) declared that Limits "attempts to blind the reader with science in the form of a pretentious array of computer printout diagrams and equations". Controversy about Limits has continued through the decades; pp 3-18 of AtKisson (2011) gives a survey. Especially in and since the 1970s, there has been a strong polarisation between most professional economists, who are dominant in business, government and education, and their critics. The first group maintains a firm commitment to growth of the kind pursued so far in the economics-as-usual period. There is, however, as indicated in Sect. 3, Environmental System Stability, strong evidence that planetary limits have been reached or at least are near. Despite this, early concerns appear to have dissipated rather than intensified. Renner (2015) writes, on p 5, "The 1992 Earth Summit in Rio de Janeiro was a milestone in global environmental consciousness. Yet in the two decades since then, the pressures on the planet's natural resources and ecological systems have only increased, and the second Rio conference- "Rio + 20" in 2012-was far less of an environmental milestone."

Renner backs this up with a table $(1.2, \mathrm{p} 10)$ showing 18 indicators of growth in that 20-year period, all but one of which show increase, ranging from 13 to $311 \%$. The single exception-a 93\% decrease in use of ozone-depleting substances-is however significant, for it shows what is possible in cases when a technical solution (substitution) is available and political will exists. Those conditions were evidently not usually present during 1992-2012.

\subsection{Technology}

Against the extreme nature of prolonged exponential growth, faith is placed by economics-as-usual in technical efficiency. Yet in general growth has exceeded technical 
efficiency gains in the economy-as-usual era. This is the nature of the economy-as-usual, which requires everexpanding markets (Foster 2000). The 'paradox' that an improvement in the efficiency of processing a resource may lead to an increase, not a decrease, in the use of that resource was noted already by William Stanley Jevons (1865) who observed (for example at p 112) that more efficient steam engines led to a greatly increased consumption of coal.

Under the conditions of economy-as-usual there are many examples of Jevons' paradox. One such is the increase in the use of paper in the computer age, contrary to much early talk of the paperless office. Sellen and Harper (2002), estimating (pp 11-12) office paper consumption, write "for worldwide consumption, the trend is a steady steep increase", a doubling between 1980 and 1997. More recently, the increase is slower but still rapid. Bajpai (2015) reports (p 2) "Globally paper use has grown an average $1.7 \%$ each year over the past decade."

Another example (Oak Ridge National Laboratory 2016) is the increasing use of petroleum by the US transportation sector. Table 1.12 of that reference includes data on 'Petroleum Production and Transportation Petroleum Consumption in Context, 1950-2015'. There is a steady (faster at first) rise throughout the period, from 3.36 million barrels/day in 1950 to $13.58 \mathrm{mb} / \mathrm{d}$ in 2015 . The only exceptions are small dips in 1973-1974 (OPEC oil embargo), 1979 (second oil shock) and 2009-2012 (result of 2007-2008 global financial crisis). The long-standing US programme 'Corporate Average Fuel Economy', which was "enacted by Congress in 1975, CAFE's purpose is to reduce energy consumption by increasing the fuel economy of cars and light trucks" (National Highway Traffic Safety Administration 2017), has produced no discernible reduction in petroleum consumption. Steps to avoid any real reduction have included successful marketing in favour of Sports Utility Vehicles (SUVs) which circumvented the fuel economy requirements (Bradsher 2002). In addition, the official fuel economy reports that became mandatory in many countries have for many years been falsified to a remarkable extent- "The gap between the fuel economy you get in the real world and the official figures that car manufacturers must quote in their brochures has been getting wider and wider. Back in 2001 the average gap was a relatively small $8 \%$ but by 2014 this had grown to 40\%." (The AA 2017).

A further unresolved issue with reliance on technological solutions within the economy-as-usual is that it reduces the need for human labour. This ought to be good. Did it not present a wonderful opportunity to transfer a large part of heavy and tedious kinds of labour to mechanical devices, computers and combinations thereof (robots and cyber-physical systems)? This has indeed been done, but in a manner that has removed stress neither from those in employment nor from those who are unemployed and at risk of being stigmatised as skivers.

\subsection{Inequality}

In general, economic inequality fell during the first twothirds of the last century but then started to rise and in recent decades is rising spectacularly (Dorling 2014; Drèze and Sen 2013). There is a strong polarisation into winners and losers. The recent political discourse (see, for example, Smith 2017) about 'rust belts' and 'left-behind' people is the current expression of a half-century trend. The separation of the rich behind walls and private green belts, the 'squeezing' of the middle class (Ho 2016) and the frustration of the humiliated poor (Laverty and Loach 2016) all contribute to conflict.

Extreme inequality is not confined to the richest nations, nor to the West. Forbes Staff (2017) report that in Malaysia, with a population of 31 millions, 12 billionaires have a combined 'net worth' equal to $15 \%$ of the country's GDP. And in Nepal, with a population of 29 millions, a single billionaire has a net worth equal to $6 \%$ of the country's GDP.

\subsection{The need for economy change}

In a rapidly changing world, economics naturally changes as well. The expression used in this paper, economy-as-usual, implies that, in popular and orthodox discourses, radical economic change (economy change) is 'off limits' but it does not mean that economics has been static during the last few decades. Deregulation, privatisation, growth, increasing role of finance, new technology and inequality are all changing aspects of the economy-as-usual. The language of economics also develops, but in a particular and limited way. It has become highly technical, not merely as used among professionals but also between other actors-political, administrative and business leaders. And a remarkable amount of this technical language is transmitted to the public by the mass media (Gingell 2015).

An important but insufficiently noticed feature of public discourse about economics is that it is strongly oriented to the quantitative. In this way, a 'normal' agenda is set, in which the assumptions of economics-as-usual are embedded and unexamined. Consequently, even critiques of economics-as-usual often look for the solution to current problems in sustainable growth, or in technology, or in green capitalism. The inadequacy of approaches of this kind is argued in, for example, Kothari, Demaria and Acosta (2014).

Economists, leaders and the public are always immersed in a complicated world. Projects include many components, with incommensurable kinds of value. Yet decisions must be made and in the end the essence of the quantification of economics-as-usual is simplistic, in that it arrives at a 
one-dimensional concept of value. At this stage, discussions are restricted to the one-dimensional line and the unit of measurement on this line is monetary value. Various different 'goods' exist but their values must somehow be quantified and compared by means of exchange rates and so brought to points on a common scale. Then, for a given set of policy choices, additions and subtractions can be done for any number of goods and a single number produced which is the net 'benefit minus cost'. Of many policy choices the best one is that with the greatest value of this single number.

Once this utilitarian mind-set is accepted, the use of mathematical analysis, within its proper domain, is appropriate, although a lot of mystification could and should be stripped away. The domain of validity of this approach is limited. If there are elements of economic importance that cannot be quantified or cannot be quantified adequately, then quantitative methods should not be used or at least not used by themselves. It is not enough simply to ignore elements of economic value that cannot be quantified, whether for technical or for societal reasons. Perhaps the most notable element omitted in economics-as-usual is the large amount of unpaid caring that people do for others and themselves (Cottey 2014, pp 23-24 of; Earle et al. 2017). Other elements that contribute to general well-being include aesthetic pleasure, learning, skills, creativity, play and appreciation of the natural world (physical and living). These are recognised inadequately by economics-as-usual.

Another damaging aspect of the restricted, quantitative concept of economic activity is its role in extreme and still rising inequality. Defenders of the astronomic incomes and assets of the richest argue that super-talented and hard-working CEOs single-handedly make the difference between success and failure of large companies; and likewise that successful traders and financiers make the difference between a growing global economy (said to be vital) and an economic recession (disastrous for all). Rewarding such exceptional people with a small fraction of the gigantic differences they make is held to be a small price for the stability and growth of 'the economy'.

Such defences of the economy-as-usual have a superficial coherence and are hard to penetrate unless buried assumptions which underlie popular economic language are revealed. For instance:-

- the terms earnings and income are often conflated

- the current primary meaning of wealth is limited to 'an abundance of valuable possessions or money'. (It could usefully be expanded and reconnected with well-being.)

- in economic contexts, the word work is restricted to income-generating activity

- striving is now sometimes used to laud an insatiable materialism while people in severe need may be denounced as skiving
- in British English, property usually means real estate and its wider sense of assets is obscured

- while time is money is too hackneyed a phrase to be widely used today, equivalences between time and money are embedded in much discourse

- growth of an economics-as-usual kind is tacitly assumed to be vital

- technical language distracts from profound injustice and suffering

- conservative economic language inhibits vision and imagination as to what is possible.

Conventional language makes the economy-as-usual seem natural and inevitable. Starting from that place, alternative ideas are harder to generate and they seem less practical. Yet the growth argument shows that the economy-as-usual is unsustainable. Radical change will happen, and on a timescale that matters to people living today. Rather that wait passively for the economy-as-usual to fail in a chaotic manner, it is better to marshal human imagination and resourcefulness in consideration of alternative economies, appropriate to the new conditions. The extremely serious issues of sustainability have led to a large literature. Among many valuable contributions are Barnett (2015), Boyle and Simms (2009), Costanza et al. (2015), Dietz and O'Neill (2013), Gang et al. (2011), Hsu (2016), Jackson (2012), Scott Cato (2011).

Radical alternatives to economy-as-usual are sometimes said to neglect human nature and human instinct. At stake here, as new external conditions press harder, is the manner in which the human response is guided in the short term by knowledge and intelligence, in the medium term by cultural evolution, and in the long term by biological evolution. The purpose of this paper is not to advocate a specific oikonomic model, apart from asserting that a civilised adaptation is worth working for-something that has never been proved impossible, even if the outlook may at present be grim. The paper does not construct scenarios. Instead, one basic principle is suggested and a few features are mentioned which could be major elements of a sustainable economy in a jurisdiction. The Basic Principle, to be honoured in practice and not merely in name, is all people have a right to the basic necessities of a civilised life.

This principle should underpin a jurisdiction's economy. Some of the important features of the economy might be (Cottey 2014):

- a universal basic income scheme (modest but enough to deliver, within the jurisdiction, the basic principle according to each person's needs)

- work defined as any systematic activity useful in creating and sustaining a good life 
- a share of useful work available to all who desire additional income

- unnecessary and harmful activity (as, for example, arising from excessive competition) to be discouraged

- deputation of arduous physical and tedious mental work to machines, while encouraging work and play that contribute to healthful physical and mental exercise

- limits, reflecting the person's circumstances, to personal assets and income.

These examples are offered as outlines of some of the possibilities opened if radical economy changes (to be expected in any case) were guided in a thoughtful, cooperative direction and not in a defensive, selfish direction.

\section{Oikonomia and conflict}

Human conflict is manifested in a great range of intensities, from minor interpersonal disagreements to existential threats. This last phrase is unfortunately not hyperbole. The Bulletin of the Atomic Scientists, from its beginning in 1945, has never shrunk from study and warning of the apocalyptic dangers associated with nuclear arsenals. More recently, BAS has added to its concerns a second existential threat-climate change. As a symbol and a warning, a Doomsday Clock, set close to midnight, has for 70 years been displayed on the Bulletin's front cover. The clock has been reset only 23 times and in late January of this year (2018) the most recent reset was made. The clock now stands at two minutes to midnight. Only once before (1953) was so dire a reset made. The clock itself is of course simplistic and for a full argument one must go to a BAS Statement (Science and Security Board of the Bulletin of the Atomic Scientists 2018). The reasons for now raising the warning level are set out in the Statement. To concerns of a longestablished nature are added (pp 3-5) something new at the highest political level-disturbing comments about the use and proliferation of nuclear weapons and rejection of the overwhelming scientific consensus on climate change.

The Statement is powerful yet one may have a sense of something missing. What this is might be deduced from the brief biographies of the (19 plus an editor) members of the Board. These biographies are very impressive but economics is hardly represented. Perhaps because of this the Statement does not ask what might underlie the noted trends. It is a theme of the present paper that economics-as-usual is a major source of dangers and that the marginalisation of thinking at the level of economy change is a major obstacle to the invention, development, testing and deployment of prospective solutions.

Before the argument of this paper proceeds further, one clarification is needed. The Bulletin of the Atomic Scientists, by virtue of its history and its role, foregrounds apocalyptic threats (albeit not exclusively). The worst nuclear weapon and climate change scenarios are distinct possibilities and they merit attention, no matter how disagreeable such attention may be. Nevertheless, there is much more to conflict than existential threats. This paper attempts to deal with human conflicts of all intensities in a unified way. It does this by noting that the sources of conflicts are conflicts of interest. Further, conflicts of interest are a part of life. There is no possibility of a civilisation without conflicts of interest. The question is-how to develop civilisation that avoids the emergence of the deadliest and most disproportionate quarrels and has in place the means for addressing as fairly and calmly as possible such conflicts of interest as do occur? It was noted in the Introduction that the economic structure of a society influences the manner in which conflicts of interest play out. The following subsections consider some aspects of this.

\subsection{Progress?}

Human conflict can be divided into three broad classes:

- conflict with the rest of nature (Beddington 2009; Brown 2011; Costanza et al. 2015; Fearnside 2015; Intergovernmental Panel on Climate Change 2017; McNeill and Engelke 2014; Parker and Davenport 2016; Renner 2015; Steffen et al. 2007; The Worldwatch Institute 2015; World Meteorological Organization 2017)

- conflict with other humans (Duchrow and Hinkelammert 2004; Dunlap 2013; Earle et al. 2017; Fielden 1969; Ho 2016; Laverty and Loach 2016)

- conflict with nature and other humans (O'Brien 2017; Science and Security Board of the Bulletin of the Atomic Scientists 2017).

It is difficult to maintain morale in the face of the information and analysis presented in such sources, frequently dealing with atrocious violence, extending even to new existential threats. In a much noted book, The Better Angels of Our Nature: the decline of violence in history and its causes, Steven Pinker (2011) made a lengthy argument for its subtitle and thereby for hope that the downward trend could be continued. The basic methodological feature that permits his startling conclusion is to count violent deaths per capita. The probability of a given individual meeting the end of their life due to violence from other humans (whether murder, judicial execution, or warfare of various kinds) is, Pinker maintains, much less now than in earlier times. Today is, in relation to our aspirations, a violent and dangerous time but earlier times were in some ways much worse.

Pinker's thesis is well-known to scholars who have studied the history of violence but is counterintuitive to nearly 
everyone else, immersed as they are in a continuous flow of dramatic — and, let it be admitted, fascinating — stories of violence, which are however atypical of human life as a whole. True (2014) is an example of many critiques of The Better Angels and Pinker (2015) is a response to several hostile reviews. The relevance of Pinker's thesis for the present paper is that it does serve as a needed corrective to the style of news about the most sensational episodes of conflict (as well as violence). On p xxvi of the Preface, Pinker writes "The shift is not towards complacency: we enjoy the peace we find today because people in past generations were appalled by the violence in their time and worked to reduce it, and so we should work to reduce the violence that remains in our time."

The question then arises-how should we best work to reduce conflict? The proposal of the present paper may be expressed thus:

- conflict derives from conflicts of interest

- conflicts of interest can be reduced but not entirely eliminated

- economics-as-usual generates and exacerbates conflicts of interest

- economics-as-usual, with its uncritical fixation on conventional growth, is unstable

- economy change, for good or ill, will come

- it is time to open economic discourse to alternatives to economics-as-usual.

\subsection{Forestalling conflicts}

Two aspects of culture which can help to forestall conflicts (without prejudice against the importance of other aspects, such as the continued development of law, justice, critical literacy, tolerance and democracy) will be discussed briefly here. They are cooperation and technology.

Concerning cooperation-in the currently dominant discourses on social matters of all kinds, individualism (in some ways a kind of antithesis of cooperation) is either openly in the foreground, or is tacitly assumed to be obvious. "If any one term captured that spirit [of the end of the 20th century] it was 'individualism"” (Lukes 2006). For an early influential promotion of individualism, see Hayek 1949. For a report on the recent and ongoing popularity, among the most powerful in the USA, of the extreme individualistic philosophy of Ayn Rand, see Freedland 2017.

An important debate about individualism versus cooperation was triggered by the essay The Tragedy of the Commons by Garrett Hardin (1968); see also Hardin's (1998) brief Postscript article. As a result of the debate it became more widely understood that the tragic progression to over-use and eventual ruin applies to unmanaged commons, of which the ocean's fish stocks are a classic example, whereas many other commons are managed successfully by the commoners (Aligica 2014; Ostrom 1990), so that enclosure (privatisation) is not necessary. The important role of everyday cooperation is not newsworthy and is under-reported and under-appreciated. The vast majority of human actions, at the micro level, are part of an intricate social web. These actions rely on past cooperations (the basis of the slow evolution of a society) and on present cooperations (since complex operations cannot otherwise be completed) and they also assume future cooperations (so that current plans have a chance of realisation). These micro-cooperations play out daily, and even minute by minute, in personal life and in business. There is no such thing as 'the' market, conceptualised as an exogenous 'invisible hand'. Rather there is an immense web of micro-interactions most of which have a cooperative nature or at least a cooperative component.

Larger than these micro-cooperative actions are innumerable social groups with an ethos of solidarity, such as intentional communities (Diggers and Dreamers 2017), social clubs, etc. For another example, in the aftermath of hurricane Katrina in New Orleans there was, as well as the widely reported anti-social behaviour, impressive spontaneous solidarity between residents and volunteer outsiders, although that was far less reported. This solidarity contrasted starkly with the inefficiency and even obstruction of the economy-as-usual authorities. All this is described eloquently in Chap. 8, 'Disaster anarchism: hurricane Katrina and the shock of recognition', of the book The Impossible Community by John P Clark (2013). Larger again are such groups as the Anecoop Group (2016), a 'coop of coops' with 69 member cooperatives growing and marketing fruit and vegetables, and the Mondragon Corporation (no date), comprising 261 businesses and cooperatives (Gallego-Bono and Chaves-Avila 2016).

An important aspect of forestalling conflict is the rate of human reproduction. The transition to a low level of conflicts of interest will likely involve a transition to a more stable global population, considerably smaller than the current 7.5 billion. The word aspect was here chosen advisedly, it being considered that the word problem in this context is unhelpful. It is not proposed here to suggest what trajectories the global human population should, could or will take in the coming decades and centuries, beyond the general observation that a globally cooperative approach is better than an individualistic or nationalistic one. In the present world situation, the encouragement of population growth as a matter of nationalistic or economic policy is especially dangerous. Solinger and Nakachi (2015) have edited "a collection of case studies that explore when and how half of the twenty most populous countries in the world invented and implemented population policies." 
Concerning technology-the manner in which technical efficiency gains are negated in the economy-as-usual is discussed in Sect. 4.2. By contrast, in a culture with a radically different economic ethos-not fixated on growth, not worshiping competition and not accepting gross inequality-technical efficiency gains could be real and substantial. One example is the development of lighting. Solidstate lighting technology fact sheet: energy efficiency of LEDs (US Department of Energy 2013) shows the great improvement in longevity and energy efficiency relative to the incandescent lighting that was widespread until quite recently. It is also, for many applications, a significant step forward relative to the various designs of fluorescent light. LED lights are, however, still at a 'middle' stage of development. The section 'Considerations for use' of Light-emitting diode (Wikipedia 2017) mentions 11 advantages and 11 disadvantages. Further improvements may be expected. Finding the best lighting system for each of the many uses is a complex matter, depending on cultural priorities. In the economy-as-usual, however, there is no evidence of an overall reduction in energy used for lighting, even in rich industrialised countries, where excessive artificial light levels are widespread. Hanson (2014) reports, in a (valid) interpretation of what Tsao and Waide (2010) write on p 278 of a long technical article, that "the result of increases in luminous efficacy has been an increase in demand for energy used for lighting that nearly exactly offsets the efficiency gains".

On the other hand, in an economy radically different from the economy-as-usual, that gave high priority to avoiding the unnecessary use of energy, substantial lighting efficiency gains would permit commensurate energy savings. In such an economy, technology is able to contribute in like manner to many aspects of life. Thus many improvements in technological efficiency, along with other changes (developments in cooperation, democracy, education, etc), contribute realand not merely promised-progress towards sustainability.

The discussion at this point is oriented to breaking free from the addiction to growth that is characteristic of economy-as-usual but there is another aspect of forestalling conflicts that must be addressed, namely the gross and increasing inequality in societies worldwide. It is to be noted here that the division is not simply between nation-states that are rich and powerful, and those that are poor and weak. The divisions between rich and poor are complex and manifold. They cut across nation-state boundaries and, if they are to be understood and addressed, must be viewed in terms of individuals, communities and cultures. The evolution of a just economy, much more egalitarian and much different from the economy-as-usual, requires, no doubt, long and arduous struggle. It is, however, possible to envision such an economy as the product of past and future developments in civilisation. This vision can be considered an expansion of the ideas of The Better Angels of our Nature (Pinker 2011) from reduction of violence to reduction of the causes of conflict.

\subsection{Addressing residual conflicts}

The current high level of individualism, competition and accumulation goes with a harsh attitude to 'losers'. In societies with enough for all, gross inequality (see, for example, Drèze and Sen 2013) denies even basic necessities to many. This is a generalised form of violence, and more specific forms of violence, such as violence against women, and violent religious strife, can be considered consequences of this general violence. If this is correct, just and equitable societies forestall, in the course of time, at least a large part of the conflict that exists in oppressive societies.

This paper foregrounds a broad concept of conflict, beyond the more restricted ideas of war, violence and peace. From a humane point of view, wars and abuses of numerous kinds are hard to contemplate in a connected and effective manner. For many, the news, which selects the most dramatic but also intractable stories, induces despair. Ultimately, the daily diet desensitises. Pinker (2011) tries to restore some hope by noting that violence was much worse in the past and that a long historical view shows that significant progress has occurred. The argument of the present paper, which is primarily about economy change, suggests a different ordering of attention. Instead of looking first to war and other forms of horrific violence, it may be more effective in the long run to attend to the conflicts of interest which generate those abuses. It is sometimes argued that abusers are themselves the victims of earlier abuse. For example, Leach, Stewart and Smallbone (2016) write on $\mathrm{p} 150$ "we found that poly-victimisation was significantly associated with sexual offending, violent offending, and general (non-sexual, non-violent) offending." This may apply to individuals, various minority groups, social classes, ethnic groups and to nations. In an oikonomia oriented to justice and moderation, conflicts of interest may be expected to be much less than in the current economyas-usual, where high levels of individualism, competition and inequality can be abusive or lead to abusive behaviour (Duchrow and Hinkelammert 2004).

Conflicts of interest will never be wholly removed but they could be much less severe than at present and much more amenable to the conflict resolution approach. Important organisations relating to conflict resolution include the Center for Nonviolent Communication (2017) and Peace Direct (2017). The methods used by these and other organisations have some impressive achievements even when embedded, as they are to date, in the economy-as-usual. If just and egalitarian economies gradually become the norm, the methods may be expected to become more widely 
understood and applied. It is not however to be expected, even in the remote future, that all conflicts can be fully resolved and it is appropriate to consider also strategies of amelioration.

\subsection{Attitudes}

It has been proposed here that economics is very important for issues of conflict of interest. The paper has, without being prescriptive, indicated some features that would foster a sustainable oikonomia, radically differing from the current economy-as-usual. Broad features of such an oikonomia include law, justice, critical literacy, tolerance, democracy, moderation, cooperation, and technological innovations (when not subverted by 'rebound' in the form of harmful economic growth). All of these broad features exist to some extent already and have done so for centuries or millennia. They exist in imperfect form, coexisting with opposing features in a state of contradiction. The gradual development of civilising features was identified in The Civilizing Process (Elias 1994), a work which Steven Pinker (2011) acknowledges (p xxiv and pp 59-61) as influencing his own work on the (per-capita) decline of violence. In the present paper, the point of view is taken that, notwithstanding the depressing diet of daily news, progress towards sustainability is possible. It is shown how the conservative nature of mainstream economic discourse is a major obstacle to the needed change of attitude. This change is from acceptance of economyas-usual as natural and inevitable to persistent attention to the realities of environment change. It is a change to a will to discover what new directions towards a sustainable culture are possible, and to a will to make appropriate changes. Some suggestions—-redefining work, basic income, asset and income limits-are made which indicate the kind of deep change required.

Deep changes such as these can only occur in parallel with deep changes of individual and collective attitudes to what is important and desirable, that is, deep changes of human values. At present, economy-as-usual, especially its commitment to growth and to a kind of primacy of property over people, represents deeply embedded values. The values of economy-as-usual have served to make possible an unprecedented level of consumption by a significant fraction of humanity but planetary boundaries have been reached. For this practical reason-quite apart from any moral reservations-economy-as-usual has run its historic course. Works and organisations that advocate value changes compatible with the necessary kind of economy change include The Center for Nonviolent Communication (Center for Nonviolent Communication 2017), The Co-operative College (Co-operative College 2017), Common Values (Bok 1995), Enough is Enough (Dietz and O'Neill 2013). The circle of solidarity of many individuals is expanding, to other humans and to life on earth, but the task ahead is immense.

This paper started from the remarkable and rapid changes underway in planet earth's environmental system. The living and non-living parts of this unitary system are all affected. Fluctuations of various kinds and magnitudes and speeds have been a feature of the earth's history since its beginning. The current changes are so great and fast that talk of a sixth mass species extinction (Hance 2015) is warranted. The political response, by power elites and other people as well, is wholly inadequate in relation to the enormous challenge. An important aspect of this failure is the theory and the practice of economics. The language in which economic matters are discussed is highly influential, affecting what is considered practical and what impractical. Current economic discourse (in economic research, teaching, advice to elites, and dissemination to the public) projects a complex multi-dimensional reality onto a one-dimensional numerical scale, the monetary measure of selected activities. Unreflective faith in this linear scale allows growth to become a fetish, something by which the well-being of the culture as a whole is judged. Humanity has invented and climbed aboard a fast machine without first learning how to control it. The machine, and we with it are in an unstable state and we do not understand that further acceleration makes matters worse. Notwithstanding the blinkered view of most economic experts, elites and other people, radical economic change will occur - for better or worse. Some broad-brush indications are here given of changes that might mitigate the current mass extinction, restore a tolerable degree of stability and improve human comfort and joy.

Acknowledgement The author acknowledges with thanks comments by P. Pickbourne.

Open Access This article is distributed under the terms of the Creative Commons Attribution 4.0 International License (http://creativeco mmons.org/licenses/by/4.0/), which permits unrestricted use, distribution, and reproduction in any medium, provided you give appropriate credit to the original author(s) and the source, provide a link to the Creative Commons license, and indicate if changes were made.

\section{References}

Aligica PD (2014) Institutional diversity and political economy: the Ostroms and beyond. Oxford University Press, Oxford

Anecoop Group (2016) Anecoop. http://anecoop.com/en. Accessed 27 March 2017

Arner DW (2007) Financial stability, economic growth, and the role of law. Cambridge University Press, Cambridge

AtKisson A (2011) Believing Cassandra: how to be an optimist in a pessimist's world (2e). Earthscan, London. The first chapter of this book is also available at https://web.archive.org/web/2012012317 3440/http://www.earthscan.co.uk/Portals/0/pdfs/Believing_Cassa ndra_Ch1.pdf. Accessed 10 Jan 2017 
Bajpai P (2015) Green chemistry and sustainability in pulp and paper industry. Springer, Berlin. https://doi. org/10.1007/978-3-319-18744-0_1

Barnett V (ed) (2015) Routledge handbook of the history of global economic thought. Routledge, London

Beckerman W (1972) Economists, scientists, and environmental catastrophe. Oxford Economic Papers, New Series, 24(3):327-344. Oxford University Press. http://www.jstor.org/stable/2662142. Accessed 10 Jan 2017

Beckett A (2017) PPE: the Oxford degree that runs Britain. The Guardian, 23 February. https://www.theguardian.com/education/2017/ feb/23/ppe-oxford-university-degree-that-rules-britain. Accessed 26 Feb 2017

Beddington J (2009) The perfect storm. Government Office for Science. Text: http://webarchive.nationalarchives.gov.uk/20121 212135622/http://www.bis.gov.uk/assets/goscience/docs/p/perfe ct-storm-paper.pdf. Slide show 1: http://webarchive.nationalar chives.gov.uk/20121212135622/http://www.bis.gov.uk/assets/ goscience/docs/s/speech-slides-the-perfect-storm-1.pdf. Slide show 2: http://webarchive.nationalarchives.gov.uk/2012121213 5622/http://www.bis.gov.uk/assets/goscience/docs/s/speec h-slides-the-perfect-storm-2.pdf. All Accessed 9 March 2009

Bernanke BS (2004) The great moderation: remarks by the Federal Reserve Board Governor Ben S. Bernanke at the meetings of the Eastern Economic Association, February 20 2004, Washington, DC. https://www.federalreserve.gov/BOARDDOCS/SPEEC HES/2004/20040220/default.htm. Accessed 16 March 2017

Bok S (1995) Common values. University of Missouri Press, Columbia

Boyle D, Simms A (2009) The new economics: a bigger picture. Earthscan, London

Bradsher K (2002) High and mighty: SUVs-the world's most dangerous vehicles and how they got that way. Public Affairs, New York

Brown LR (2011) World on the edge: how to prevent environmental and economic collapse. Earthscan, London. Supporting data and other information is available at http://www.earth-policy.org/ books/wote/wote_data. Accessed 11 March 2017

Butler E (1985) Milton Friedman: a guide to his economic thought. Gower/Maurice Temple Smith, London

Center for Nonviolent Communication (2017) The center for nonviolent communication: making the world a more compassionate place through nonviolent communication. http://www.cnvc.org. Accessed 2 April 2017

Clark JP (2013) The impossible community: realizing communitarian anarchism. Bloomsbury, New York

Costanza R, Cumberland JH, Daly H, Goodland R, Norgaard RB, Kubiszewski I, Franco C (2015) An introduction to ecological economics, 2 edn. CRC Press, Boca Raton

Cottey A (2014) Technologies, culture, work, basic income and maximum income. AI Society 29(2):249-257. https://doi.org/10.1007/ s00146-013-0480-0. Author's accepted manuscript available at uea.ac.uk/ c013/v2/tcwbimi-final.pdf. Accessed 10 Jan 2017

Crutzen PJ (2002) Geology of mankind. Nature 415(6867):23-23

Diamond J (2005) Collapse: how societies choose to fail or survive. Allan Lane, London

Diamond J (2010) Two views of collapse. Nature 463(7283):880-881

Dietz R, O'Neill DW (2013) Enough is enough: building a sustainable economy in a world of finite resources. Berrett Koehler, San Francisco

Diggers and Dreamers (2017) Diggers and dreamers: the guide to communal living in Britain. http://www.diggersanddreamers.org.uk. Accessed 1 July 2017

Dorling D (2014) Inequality and the one percent. Verso, London

Drèze J, Sen A (2013) An uncertain glory: India and its contradictions. Allen Lane, London
Duchrow U, Hinkelammert FJ (2004) Property for people, not for profit: alternatives to the global tyranny of capital. Zed Books, London

Dunlap RE (2013) Climate change skepticism and denial: an introduction. Am Behav Sci 57(6):691-698. https://doi.org/10.1177/00027 64213477097

Earle J, Moran C, Ward-Perkins Z (2017) The econocracy: the perils of leaving economics to the experts. Manchester University Press, Manchester

Elias N (1994) The civilizing process. Translated by E Jephcott. Blackwell, Oxford (First publishedtwo volumes1939 by Haus zum Falker, Basel)

Elliott L (2011) Global financial crisis: five key stages 2007-2011. The Guardian, 7 August. https://www.theguardian.com/busin ess/2011/aug/07/global-financial-crisis-key-stages. Accessed 16 March 2017

Fearnside PM (2015) Deforestation soars in the Amazon. Nature 521(7553):423-423. https://doi.org/10.1038/521423b

Feser E (ed) (2006) The Cambridge companion to Hayek. Cambridge University Press, Cambridge

Fielden J (1969) The curse of the factory system. Frank Cass, London (First published 1836 by A Cobbett, London)

Foldvary F (2015) The market economy. Business Expert Press, New York, NY

Forbes Staff (2017) The world's billionaires 2017: Malaysia, Monaco, Morocco, Nepal, Netherlands. Forbes Asia 13(3):096-096

Foster JB (2000) Capitalism's environmental crisis-is technology the answer? Monthly Rev 52(7):1-13

Freedland J (2017) Goddess of the new right. The Guardian, section G2, 11 April:6-9. https://kielarowski.net/2017/04/12/ayn-randrules-the-world-how-she-conquered-silicon-valley-and-donal d-trump. Accessed 20 April 2017

Gallego-Bono JR, Chaves-Avila R (2016) Innovation cooperative systems and structural change: an evolutionary analysis of Anecoop and Mondragon cases. J Bus Res 69(11):4907-4911. https://doi. org/10.1016/j.jbusres.2016.04.051

Gang F, Stern N, Edenhofer O, Shanda X, Eklund K, Ackerman F, Lailai L, Hallding K (2011) The economics of climate change in China. Earthscan, London

Gatusso J-P, Hansson L (2011) Ocean acidification. Oxford University Press, Oxford

Gingell J (2015) Economics jargon promotes a deficit in understanding. The Guardian, 14 August. https://www.theguardian.com/media/ mind-your-language/2015/aug/14/economics-jargon-promotes-adeficit-in-understanding. Accessed 10 Feb 2017

Hance J (2015) How humans are driving the sixth mass extinction. The Guardian 20 October. https://www.theguardian.com/environment/ radical-conservation/2015/oct/20/the-four-horsemen-of-the-sixth -mass-extinction. Accessed 5 April 2017

Hanson D (2014) Drowning in light. Nautilus, Issue 11, March 6. http:// nautil.us/issue/11/light/drowning-in-light. Accessed 31 March 2017

Hardin G (1968) The tragedy of the commons. Science 162(3859): $1243-1248$

Hardin G (1998) Extensions of 'the tragedy of the commons'. Science 280(5364):682-683

Hayek FA (1949) Individualism and economic order. Routledge and Kegan Paul, London

Henriques URQ (1971) The early factory acts and their enforcement. Historical Association, London

Ho DWL (2016) The middle class has become more squeezed: does globalization matter? Glob Stud J 9(3):11-20

Hsu S (2016) Economic reform in Asia. Edward Elgar, Cheltenham

Intergovernmental Panel on Climate Change (2017) Fifth Assessment report (AR5). http://www.ipcc.ch/report/ar5. Accessed 8 March 2017 
Jackson R (2012) Occupy World Street: a global roadmap for radical economic and political reform. Green Books, Totnes

Jevons WS (1865) The coal question. Macmillan, London

Kant I (1795) Perpetual peace. Translated and edited by L W Beck (1957) Bobbs-Merrill, New York

Kothari A, Demaria F, Acosta A (2014) Buen vivir, degrowth and ecological swaraj: alternatives to sustainable development and the green economy. Development 57(3-4):362-375

Lanchester J (2014) How to speak money: what the money people say - and what they really mean. Faber and Faber, London

Laverty P, Loach K (2016) I, Daniel Blake. http://www.metacritic.com/ movie/i-daniel-blake. Accessed 10 Jan 2017

Lawlor R (2016) The absurdity of economists' sacrifice-free solutions to climate change. Ethics, Policy and Environment 19(3):350-365. https://doi.org/10.1080/21550085.2016.1226239. Accessed 21 March 2017

Leach C, Stewart A, Smallbone S (2016) Testing the sexually abused sexual abuser hypothesis: a prospective longitudinal birth cohort study. Child Abuse Negl 51:144-153. https://doi.org/10.1016/j. chiabu.2015.10.024

Lucas R (2003) Macroeconomic priorities: Presidential address to the American Economics Association. Am Econ Rev 93(1):1-14

Lukes S (2006) Individualism. EPCR Press, Colchester

Marsh GP (2014) The Earth as modified by human action. Editora Griffo, www.editoragriffo.com. (A new edition of Man and Nature; reprint of corrected English edition based on the Italian translation. In: Sampson Low, 1864, First edn. Son and Marston, London

McAnany PA, Yoffee N (eds) (2010) Questioning collapse: human resilience, ecological vulnerability, and the aftermath of empire. Cambridge University Press, Cambridge

McNeill JR (2000) Something new under the sun: an environmental history of the twentieth century. Allen Lane, London

McNeill JR, Engelke P (2014) The great acceleration: an environmental history of the Anthropocene since 1945. Belknap Press, Cambridge

Meadows DH, Meadows DL, Randers J, Behrens III, W W (1972). The limits to growth. Universe Books, New York

Milman O (2017). EPA head Scott Pruitt denies that carbon dioxide causes global warming. The Guardian 9 March. https://www. theguardian.com/environment $/ 2017 / \mathrm{mar} / 09 /$ epa-scott-pruitt-carbo n-dioxide-global-warming-climate-change. Accessed 10 March 2017

Minsky HP (1986) Stabilizing an unstable economy. Yale University Press, New Haven

Mondragon Corporation (no date) Mondragon (2017) http://www. mondragon-corporation.com/en. Accessed 1 July 2017

Mooney C, Dennis B, Mufson S (2016) Trump names Scott Pruitt, Oklahoma attorney general suing EPA on climate change, to head the EPA. Washington Post, 8 December. https://www.washington post.com/news/energy-environment/wp/2016/12/07/trump-names -scott-pruitt-oklahoma-attorney-general-suing-epa-on-climatechange-to-head-the-epa. Accessed 16 April 2017

National Highway Traffic Safety Administration (2017) Corporate average fuel economy. https://www.nhtsa.gov/laws-regulations/corpo rate-average-fuel-economy Accessed 31 March 2017

O'Brien S (2017) USG/ERC Stephen O'Brien statement to the security council on missions to Yemen, South Sudan, Somalia and Kenya and an update on the Oslo conference on Nigeria and the Lake Chad region: a report from UN office for the coordination of humanitarian affairs. 10 March. http://reliefweb.int/report/ yemen/usgerc-stephen-o-brien-statement-security-council-missi ons-yemen-south-sudan-somalia. Accessed 12 March 2017

Oak Ridge National Laboratory (2016) Transportation energy data book, edition 35. cta.ornl.gov/data/Chapter1.shtml. Accessed 16 April 2017
Ostrom E (1990) Governing the commons: the evolution of institutions for collective action. Cambridge University Press, Cambridge (also reprinted 2015)

Parker A, Davenport C (2016) Donald Trump's energy plan: more fossil fuels and fewer rules. New York Times, May 26. https://www. nytimes.com/2016/05/27/us/politics/donald-trump-global-warmi ng-energy-policy.html?_r=0. Accessed 21 March 2017

Peace Direct (2017) Peace direct: dedicated to stopping wars, one person at a time. https://www.peacedirect.org. Accessed 2 April 2017

Pecl GT, Araújo MB, Bell JD et al (2017) Biodiversity redistribution under climate change: impacts on ecosystems and human well-being. Science 355(6332; 31 Mar): eaai9214. doi: 10.1126/ science.aai9214 http://science.sciencemag.org/content/355/6332/ eaai9214.full. Accessed 5 April 2017

Petit ML (1990) Control theory and dynamic games in economic policy analysis. Cambridge University Press, Cambridge

Pinker S (2011) The better angels of our nature: the decline of violence in history and its causes. Allen Lane, London

Pinker S (2015) Response to the book review symposium: Steven Pinker, The better angels of our nature. Sociology 49(4):NP3NP8. https://doi.org/10.1177/0038038514556797

Renner M (2015) The seeds of modern threats. In: The Worldwatch Institute (ed) The state of the world 2015: confronting hidden threats to sustainability. Island Press, Washington, DC, pp 3-17

Schutz E (1999) Capitalism. In: O'Hara PA (ed) Encyclopedia of political economy. Routledge, London, pp 67-69

Science and Security Board of the Bulletin of the Atomic Scientists (2018) It is now two minutes to midnight: 2018 doomsday clock statement. 25 January https://thebulletin.org/2018-doomsdayclock-statement. Accessed 5 February 2018

Scott Cato M (2011) Environment and economy. Routledge, London

Seidov D, Haupt B, Masline J M (eds) (2001) The oceans and rapid climate change. American Geophysical Union, Washington, DC

Sellen AJ, Harper RHR (2002) The myth of the paperless office. MIT Press, Cambridge

Smith W (2017) Almost everyone left behind. Publishers Weekly January 23. 264(4):36-37

Solinger R, Nakachi M (2015) Reproductive states: global perspectives on the invention and implementation of population policy. Oxford University Press, New York

Steffen W, Crutzen PJ, McNeill JR (2007) The Anthropocene: are humans now overwhelming the great forces of nature. Ambio 36(8):614-621

Terzi A (1999) Animal spirits. In: O’Hara PA (ed) Encyclopedia of political economy. Routledge, London, pp 16-18

The AA (2017) Official fuel consumption figures. http://www.theaa .com/driving-advice/fuels-environment/official-fuel-consumptio n-figures. Accessed 31 March 2017

The Co-operative College (2017) Co-operative college: an educational charity dedicated to the promotion of co-operative values, ideas and principles within co-operatives, communities and society. https://www.co-op.ac.uk. Accessed 2 April 2017

The Worldwatch Institute (2015) The state of the world 2015: confronting hidden threats to sustainability. Island Press, Washington, DC

True J (2014) Are war and violence really in decline? Australian Journal of International Affairs 68(5):487-494 https://doi.org/10.108 0/10357718.2014.947354. Accessed 26 March 2017

Tsao JY, Waide P (2010) The world's appetite for light: empirical data and trends spanning three centuries and six continents. Leukos, the Journal of the Illuminating Engineering Society of North America 6(4):259-281 (2010) http://www.sandia.gov/ jytsao/ tsao_jy_2010_04_app_for_light_LEUKOS.pdf. Accessed 31 March 2017

United Nations Population Fund (2016) State of world population 2016. http://www.unfpa.org/swop. Accessed 8 March 2017 
US Department of Energy (2013) Solid-state lighting technology fact sheet: energy efficiency of LEDs. http://www.hi-led.eu/wp-conte nt/themes/hiled/pdf/led_energy_efficiency.pdf. Accessed 28 March 2017

Wikipedia (2017) Light-emitting diode. https://en.wikipedia.org/wiki/ light-emitting_diode. Accessed 29 June 2017
World Meteorological Organization (2017) Climate breaks multiple records in 2016, with global impacts. Press release number 04/2017, published 21 March 2017. https://public.wmo.int/en/ media/press-release/climate-breaks-multiple-records-2016-globa 1-impacts. Accessed 21 March 2017 